\title{
Atenção Integral ao Paciente Chagásico. Uma proposta para o cuidar
}

\author{
Wilson de Oliveira Jr. \\ Recife, PE
}

O modelo de crescimento econômico adotado no nosso país contribuiu sobremaneira para o êxodo rural com migração dos indivíduos para as grandes cidades, em busca de melhores oportunidades de emprego, propiciando a migração rural-urbana do paciente chagásico e provocando, assim, a chamada urbanização da doença. A doença de Chagas passou a surgir com maior freqüência nos serviços de saúde urbanos, estimando-se hoje que cerca de $60 \%$ a $70 \%$ dos pacientes resida em grandes centros, sobretudo na periferia, em condição socioeconômica tão precária como aquela vivenciada no meio rural ${ }^{1}$.

Nas últimas duas décadas do século passado, houve consideráveis avanços no controle da doença de Chagas, não somente com ações voltadas para o combate vetorial, como também no que se refere à transmissão transfusional. Sinalizando, positivamente, para a eficácia das ações adotadas, torna-se cada vez mais raro o encontro de pacientes na fase aguda.

Embora não possamos negar tais conquistas, estima-se que, a cada ano no Brasil, cerca de 6 mil pacientes faleceram por causas relacionadas à doença, fazendo com que a doença de Chagas continue sendo considerada como um importante problema da saúde pública brasileira, na medida em que existem cerca de 3.5 milhões de pacientes crônicos remanescentes, dos quais $20 \%$ a $30 \%$ apresentam comprometimento cardíaco $^{1}$.

Essa situação decorre não só dos fatores - determinantes - da precária condição de saúde da população brasileira, mas, também de algumas peculiaridades próprias, que devem ser salientadas: 0 paciente chagásico pertence a um segmento da população de baixíssima estratificação social, excluído pela fatídica conjunção pobreza e doença, o que lhe confere pouco poder de reivindicação e praticamente nenhuma visibilidade política. 0 contrário se observa em portadores de outras doenças, como a AIDS, cujo poder de mobilização tem conseguido grande prioridade em medidas de atenção, por parte do poder público. Outro fato freqüentemente observado é a doença de Chagas não conferir status àqueles que dela se ocupam, desestimulando o envolvimento de mais profissionais, sobretudo no âmbito da Cardiologia. Esta constatação revela-se na progressiva perda de prioridade do tema em eventos científicos e se alia ao desinteresse notório da indústria farmacêutica,

Hospital Universitário Oswaldo Cruz - UPE

Endereço para correspondência: Wilson de Oliveira Jr. - Rua Arnóbio Marques, 310 - Cep 50100-130 - Recife - PE

Email:woliveirajr@uol.com.br

Recebido para publicação em 19/09/004

Aceito em 08/11/2004 quer no desenvolvimento de novos fármacos capazes de intervir, eficazmente, no curso crônico da doença, quer no apoio ao estudo e à pesquisa.

Dentro desse contexto, e almejando ampliar o atendimento ao grande número de pacientes chagásicos assistidos no Hospital Universitário Oswaldo Cruz-HUOC, da UPE, surgiu em 1987 o Ambulatório de Doença de Chagas $^{1}$, ligado ao grupo de Miocardiopatias e de Insuficiência Cardíaca. A proposta inicial, que se consolidou ao longo dos anos, foi propiciar uma atenção integral ao portador da doença, traduzida em ações não de tratamento apenas, mas de cuidado com um enfoque biopsicossocial.

A atenção integral tem como necessidade básica a formação de uma equipe multiprofissional tecnicamente bem preparada e sintonizada com a ideologia do cuidar. Apesar das dificuldades encontradas, aos poucos, novos profissionais foram abraçando a causa e a equipe criada, atualmente está composta por: médico cardiologista, assistente social, psicóloga, enfermeira, nutricionista, professora e auxiliares de enfermagem.

No organograma do Ambulatório de Doenças de Chagas encontram-se as Unidades de Insuficiência Cardíaca e Arritmias, além dos Núcleos de Apoio, destacando-se o Núcleo de Apoio com assistência diferenciada ao doador soro-positivo e ao chagásico idoso, o Núcleo de Apoio Psicossocial e o Núcleo Educacional.

0 ambulatório põe à disposição dos seus pacientes exames básicos utilizados na investigação da doença de Chagas, além de teste ergométrico, ecodopplercardiografia, eletrocardiografia dinâmica, tilt test, estudo eletrofisiológico, cateterísmo cardíaco, endoscopia digestiva alta e colonoscopia. Os tratamentos sintomático e etiológico são realizados quando indicados, assim como em casos mais específicos, implante de marcapasso e ou cardiodesfibrilador.

Embora o foco prioritário seja atuar na área assistencial, devido à grande demanda existente, a pesquisa e o ensino, também têm permeado suas ações, através da participação em ensaios multicêntricos, encontros científicos, produção de teses, artigos em periódicos e livros

Nestes 18 anos de funcionamento, o ambulatório de Chagas, como é conhecido, tornou-se referência para o Estado de Pernambuco, com 1.850 pacientes matriculados, realizando em 2003, 13.292 consultas, média de 1.200 consultas/mês. 0 perfil dos pacientes atendidos se caracteriza por adultos entre 30 a 50 anos, com predominância do sexo feminino, procedência rural, baixo nível socioeconômico, com precária qualificação profissional e escolar, residentes na periferia da região metropolitana do Recife.

Uma vez acolhido pelo serviço, o paciente é submetido a testes sorológicos confirmatórios, eletrocardiograma e radiografia de tórax, no sentido de classificar o estágio de comprometimento 
cardíaco da doença. Assim, dependendo do grau, a doença poderá ser estadiada no paciente em três níveis: estágio 1 quando apresenta sorologia positiva, encontra-se assintomático e possui eletrocardiograma e radiografia de tórax normais; estágio 2 , quando apresenta alterações no eletrocardiograma, quer seja por arritmia de condução, ventricular ou ambas, radiografia de tórax com ICT $<0,55 \mathrm{~cm}$, porém sem sinais de insuficiência cardíaca; estágio 3 encontra-se nos pacientes mais graves com eletrocardiograma francamente patológico e radiografia de tórax com ICT $>0,55 \mathrm{~cm}$, apresentando evidente insuficiência cardíaca congestiva, podendo ou não cursar com arritmias.

Na dependência do estágio da doença, haverá complementação diagnóstica, quer na esfera cardíaca e/ou digestiva, com determinação da conduta terapêutica adequada, além da identificação de possíveis comorbidades. 0 estágio da doença também determinará a periodicidade do atendimento e, dentro do possível, o paciente será atendido pelo mesmo médico, objetivando estabelecer um maior vínculo terapêutico.

O Serviço oferece ao paciente acesso a interconsultas, atendimento emergencial, internamento nas intercorrências e também acesso à avaliação epidemiológica de outros casos na família. Além da consulta médica, o chagásico é atendido pelos demais profissionais da equipe, quando é avaliada sua situação socioeconômica (de trabalho, previdenciária, suporte familiar etc.) bem como suas expectativas sobre a doença e o seu tratamento. Nessa abordagem, os aspectos médico-trabalhistas são observados, no que se refere à inserção no mercado de trabalho,terreno em que pode ocorrer a errônea exclusão de pacientes apenas com sorologia reagente (forma indeterminada da doença). Orientação para situações especiais, tais como gestação, cirurgias, prática de exercícios e a conscientização para a não-doação de sangue e de órgãos é enfatizada?

Ainda em 1987, sob o incentivo do modelo da assistência integral, estimulou-se a criação da Associação dos Portadores de Doença de Chagas de Pernambuco, defendendo o lema: "Um Compromisso com a Vida". A associação é uma entidade sem fins lucrativos, sem vinculação político-partidária, cuja diretoria é composta por pacientes eleitos em assembléia, com gestão de dois anos. Desenvolve suas ações de forma coadjuvante com o trabalho realizado pelo ambulatório, contando com atividades de apoio, que também se estendem à área educacional. Nas reuniões semanais, são abordados temas relacionados à saúde, à doença de Chagas, particularmente enfatizando-se questões que dizem respeito ao estigma da doença, ao implante e funcionamento do marcapasso, procurando desfazer fantasias a respeito. Promove também curso regular de alfabetização e de capacitação profissional, além de publicações educativas, como a "Cartilha do Portador de Doença de Chagas".

A associação desenvolve ações de apoio, através da aquisição mais econômica de medicamentos para o ambulatório, para distribuição gratuita, sobretudo aos pacientes mais carentes, reduzindo a escassez de recursos terapêuticos. O aporte financeiro é oriundo da participação de sócios contribuintes e mantenedores, doações de pessoas físicas e jurídicas, da realização de feiras mensais de objetos doados para angariar fundos, assim como da venda de material promocional em eventos da área da saúde. A iniciativa tem tido repercussões bastante positivas, tanto assim que a experiência por nós vivenciada tem servido de estímulo para a criação de outras associações no Brasil e mais recentemente em Buenos Aires, Argentina (em fase de implantação).

Nos 18 anos de atuação do ambulatório, o modelo adotado tem se mostrado eficaz na atenção a uma doença crônica e estigmatizante, como a doença de Chagas. É notório os reflexos positivos na qualidade de vida dos nossos pacientes, embora não possamos afirmar que haja verdadeiramente um impacto positivo sobre a mortalidade. A atenção integral refere-se à assistência ao paciente chagásico em sua globalidade, levando em consideração o conjunto de determinantes biológicos, psicológicos e sociais, pois não podemos esquecer que o ser humano é a resultante da interseção desses fatores. Este olhar mais abrangente, ajuda na tomada de decisões mais próximas da sua realidade. A proposta de cuidar do portador de doença de Chagas transcende o ato, não raro mecânico de tratar, na medida em que envolve uma complexidade que requer de todos os profissionais envolvidos, profundo compromisso, acima de tudo, com a pessoa do paciente.

\section{Referência}

1. Dias JCP. O Desafio da Doença de Chagas nos Centros Urbanos. Revista da Soc Bras Med 1999; 32 (sup II): 45-8.
2. Oliveira W Jr. O Cardiopata Chagásico em Situações Especiais in Clínica e Terapêutica da Doença de Chagas: uma Abordagem Prática para o Clínico Geral. Jcp Dias e Jr. Coura, Ed Fiocruz, Rio de Janeiro, 1997; 293-322. 